\title{
Análisis de la investigación sobre la historia y evolución de las relaciones públicas y la comunicación corporativa en España
}

\section{Analysis of the research on the history and evolution of public relations and corporate communication in Spain}

\author{
Susana Miquel-Segarra. Universitat Jaume I (|smiquel@uji.es) \\ Marián Navarro-Beltrá. Universidad Católica de Murcia (mnavarro2@ucam.edu)
}

Recibido el: 01/02/16 - Aceptado el: 16/03/16

\section{Resumen:}

La investigación sobre la historia y evolución de las relaciones públicas y la comunicación corporativa en España ha sido difusa entre los académicos de este país. Pese a que desde la implantación de la formación universitaria, tanto profesión como disciplina, han ido aumentando a un ritmo vertiginoso, el debate y las diferentes posiciones sobre sus orígenes e identidad siguen vigentes. Esta investigación pretende analizar las similitudes y diferencias que hay entre las distintas posturas existentes, así como la evolución hasta nuestros días de las "relaciones públicas” y el viraje que se ha producido, sobre todo en el ámbito profesional, hacia la "comunicación corporativa”. Para acometer esta investigación se ha realizado una revisión bibliográfica a partir del análisis de la literatura publicada en las principales bases de datos de Ciencias Sociales de España. Los principales resultados indican que existe disparidad de criterios sobre los antecedentes y orígenes de las relaciones públicas en España así como sobre su evolución hacia la comunicación corporativa.

Palabras clave:

Relaciones públicas; comunicación corporativa; historia de las relaciones públicas; orígenes de las relaciones públicas

\section{Abstract:}

Research on the history and evolution of public relations and communication management in Spain has been diffused among academics. Although since the introduction of university, both profession and discipline have been increasing at a rapid pace, the debate and the different positions about their origins and identity are still valid. The purpose of this research is to analyze the similarities and differences that exist between the different currents in the Spanish academic field, as well as the current evolution of "public relations" and the change in direction that has occurred, especially in the professional field, towards "communication management". To carry out this investigation a bibliographic review has been carried out from the analysis of the literature published in the major Social Sciences databases in Spain. The main results indicate that there is disparity of criteria on the background and origins of public relations in Spain as well as their evolution towards communication management.

\section{Keywords:}

Public relations; communication management; public relations history; public relations; background 


\section{Introducción}

La gran mayoría de los académicos que han estudiado el origen de la actividad de las relaciones públicas en España no dudan en situar sus orígenes entre los años 50 y 60. Si bien este dato, junto con la reconocida influencia norteamericana sobre la disciplina o la consideración de Maestre como el padre de las relaciones públicas en España son verdades reconocidas de forma generalizada, investigaciones más recientes muestran ciertas discrepancias con estas afirmaciones. En la actualidad conviven diferentes corrientes teóricas que explican la historia y evolución de las relaciones públicas en España. Así, existe un grupo de académicos que defiende el origen estadounidense del término y su implantación en España entre los años 60 y 70. Esta corriente mantiene el uso del término "relaciones públicas" para hacer referencia a una disciplina que ha evolucionado y ampliado sus funciones, pero no ha variado su denominación (Arceo, 2006). Sin embargo, existen otros sectores que, por diferentes motivos, difieren de esta postura tanto en los orígenes como en la evolución. De esta forma, se encuentran diversos autores que apoyan la idea de que las relaciones públicas ya se daban en España antes de la llegada del concepto norteamericano (Rodríguez, 2007; Armendáriz, 2012; Reina, 2014a; Reina, 2014b; Reina y González, 2015).

En cuanto a la evolución del término, es importante destacar varios momentos significativos. Por un lado, y de manera irrefutable, el final del franquismo y la llegada de la democracia creó un nuevo contexto político y socieconómico, pero también comunicativo, que propició el desarrollo de las relaciones públicas. Por otro lado, y como punto de inflexión para la disciplina, vemos cómo entre los años 80 y 90 aparece una corriente basada en la escuela francesa que defiende una visión integral de la comunicación. Este enfoque supera el concepto de "relaciones públicas" (Costa, 1995, 2001; 2009; Villafañe, 1999; Martín, 2007) y evoluciona hacia un nuevo término ("comunicación corporativa") y su práctica profesional adquiere el nombre de "dirección de comunicación” (Míguez y Baaomonde, 2011).

Villafañe (1999) señala que la aparición de esta nueva corriente es motivada por las nuevas necesidades comunicativas que surgen tras la crisis que el sector publicitario sufrió a finales de los 80. Para Villafañe, esta crisis propicia que emerjan "otros procesos de comunicación aplicada con una clara tendencia a transmitir atributos de identidad de las empresas a audiencias cada vez más fragmentadas agrupadas en torno a valores, mucho más intangibles que los tradicionales criterios de segmentación de mercados, como los estilos de vida o los valores culturales" (1999: 220). Este mismo autor afirma que la imagen de la empresa "no solo comienza a revalorizarse sino que se convierte, en muchos casos, en el principal objetivo de su comunicación" (Villafañe, 1999: 223). Este giro favorece la aparición de departamentos y consultoras de relaciones públicas y comunicación que, con una perspectiva sistémica, quieren integrarse en las organizaciones como un elemento esencial que permita unir transversalmente los distintos departamentos de una empresa a través de la comunicación corporativa. 
En la actualidad en España sigue habiendo mucha confusión sobre la disciplina de la comunicación corporativa y toda la terminología que la rodea. Así, se pueden encontrar numerosos términos que denominan un mismo fenómeno con matices relacionados, principalmente, con las funciones que desarrollan sus profesionales (DIRCOM, 2013).

Asimismo, coexisten diferentes posiciones acerca de la evolución de la disciplina. Para autores como Almansa (2005), los gabinetes de prensa han evolucionado hacia gabinetes de comunicación y dicha evolución ha sido causada principalmente por la ampliación de funciones. En los actuales gabinetes las relaciones informativas son junto con la comunicación interna y la comunicación de producto las principales funciones (Almansa, 2005). Estas funciones coinciden con las cuatro parcelas en las que Villafañe divide el corporatel (Villafañe, 1999: 11): "Las relaciones con la prensa, la comunicación corporativa, la comunicación de producto y la comunicación interna".

La importancia que la evolución de las relaciones públicas ha tenido para el ejercicio de la profesión y su desarrollo académico ha supuesto la existencia de recientes investigaciones que han analizado esta disciplina. Sin embargo, no son muchos los estudios que la hayan revisado y comparado. En este sentido encontramos algunos trabajos como los realizados por Gutiérrez y Rodríguez (2009) y Míguez y Baamonde (2011). Ante este contexto, resulta interesante compilar la producción científica referente al ámbito de estudio para conocer el panorama general de las distintas posiciones que los académicos tienen sobre la historia y evolución de las relaciones públicas y la comunicación corporativa en España. Resulta especialmente relevante prestar atención a los orígenes más remotos de las relaciones públicas por su falta de estudio.

Así, el objetivo general de esta investigación es analizar el origen y la evolución que las relaciones públicas y la comunicación corporativa han tenido en España, prestando especial atención a los diferentes planteamientos realizados por los académicos. Específicamente se pretende:

a) Conocer las diferentes posturas de los académicos ante el nacimiento de las relaciones públicas;

b) Describir la evolución del concepto de “relaciones públicas” a “dirección de comunicación” en España desde sus inicios hasta principios del siglo XXI;

c) Contrastar los diferentes personajes e hitos relevantes en la evolución práctica profesional y la teoría;

d) Detectar las concomitancias y puntos de inflexión que existen entre las diferentes corrientes de los académicos.

Villafañe se refiere al corporate como "todos aquellos aspectos procedimientos, instrumentos, etc., que persiguen construir una determinada imagen corporativa". 


\section{Metodología}

Con el fin de alcanzar los objetivos planteados se recurre a la metodología cualitativa y, en concreto, se realiza una revisión bibliográfica de textos vinculados con los orígenes y la evolución de la comunicación en las organizaciones.

El universo de estudio ha estado formado por la totalidad de los artículos vinculados con el tema de la investigación y publicados en España entre 1972 (año en el que se implanta la titulación de Publicidad y Relaciones Públicas en las universidades españolas) y septiembre de 2015 (momento en el que se realiza la recogida de datos) en revistas científicas indexadas en las bases de datos Dialnet e ISOC.

La estrategia de búsqueda principal se ha basado en localizar, en el título y en el resumen de los documentos, determinadas palabras clave. Los términos introducidos en las bases de datos se pueden agrupar en tres categorías: a) relacionados con el origen de la materia, b) relacionados con la comunicación y c) relacionados con la delimitación geográfica. En concreto, las palabras utilizadas se pueden observar en el cuadro 1:

Cuadro 1. Términos introducidos en las bases de datos por categorías

\begin{tabular}{|c|c|c|}
\hline \multicolumn{3}{|c|}{ Términos especificados en las búsquedas } \\
\hline $\begin{array}{l}\text { Relacionados con el } \\
\text { origen de la materia }\end{array}$ & $\begin{array}{l}\text { Relacionados con la } \\
\text { comunicación }\end{array}$ & $\begin{array}{c}\text { Relacionados con el } \\
\text { territorio }\end{array}$ \\
\hline $\begin{array}{l}\text { Histor* } \\
\text { Antec* } \\
\text { Evoluc* }\end{array}$ & $\begin{array}{c}\text { Relaciones públicas } \\
\text { Dirección de } \\
\text { comunicación } \\
\text { Comunicación } \\
\text { corporativa }\end{array}$ & España \\
\hline
\end{tabular}

Fuente: Elaboración propia

La segunda estrategia de búsqueda se ha centrado en la utilización de filtros. Así, se han delimitado las características de los documentos localizados a través de las bases de datos seleccionadas. En concreto, se ha acotado el tipo de documento (artículos de revista), la materia (ciencias sociales) y el país (España).

Tras localizar los textos, se han seleccionado únicamente aquellos que cumplen con ciertos criterios de inclusión: artículos publicados en España entre 1972 y 2015 relacionados con el estudio de los orígenes y la evolución de la comunicación en las organizaciones. 
A partir de la lectura del título, del resumen o del texto completo de los documentos, se ha considerado que han cumplido los criterios de inclusión 15 artículos (ver cuadro 2). Para la realización de los resultados se han tenido en cuenta los escritos anteriormente mencionados así como la bibliografía que en ellos se cita.

Cuadro 2. Artículos obtenidos como resultado de la búsqueda.

\begin{tabular}{|c|c|c|c|}
\hline Autores & Año & Artículos & Revista \\
\hline \multirow{2}{*}{ Almansa, A. } & 2005 & "Relaciones públicas y gabinetes de comunicación”. & $\begin{array}{l}\text { Anàlisi: Quaderns de comu- } \\
\text { nicació i cultura }\end{array}$ \\
\hline & 2004 & $\begin{array}{l}\text { "Historia de los gabinetes de comunicación en Es- } \\
\text { paña” }\end{array}$ & $\begin{array}{l}\text { Historia y Comunicación } \\
\text { Social }\end{array}$ \\
\hline Arceo & 2006 & "La investigación de relaciones públicas en España" & $\begin{array}{l}\text { Anàlisi: Quaderns de comu- } \\
\text { nicació i cultura }\end{array}$ \\
\hline Armendáriz, E. & 2012 & $\begin{array}{l}\text { “Relaciones públicas pioneras en España. Algunos } \\
\text { precedentes en la primera mitad del siglo XX y } \\
\text { pasos preliminares de la nueva profesión”. }\end{array}$ & $\begin{array}{l}\text { Anàlisi: Quaderns de comu- } \\
\text { nicació i cultura }\end{array}$ \\
\hline Casado, A.M. & 2013 & $\begin{array}{l}\text { "La gestión de la reputación en España: nuevas ten- } \\
\text { dencias en las direcciones de comunicación”. }\end{array}$ & $\begin{array}{l}\text { Miguel Hernández Commu- } \\
\text { nication Journal }\end{array}$ \\
\hline García, J. V. & 2011 & $\begin{array}{l}\text { "Los responsables de comunicación en la empresa } \\
\text { española desde la década de los setenta hasta hoy } \\
\text { día: evolución de funciones y perfiles profesionales". }\end{array}$ & $\begin{array}{l}\text { Revista Internacional de las } \\
\text { Relaciones Públicas }\end{array}$ \\
\hline $\begin{array}{l}\text { Gutiérrez García, E. y Rodrí- } \\
\text { guez Salcedo, N. }\end{array}$ & 2009 & $\begin{array}{l}\text { "Cincuenta años de Relaciones Públicas en España. } \\
\text { De la propaganda y la publicidad a la gestión de la } \\
\text { reputación” }\end{array}$ & Doxa Comunicación \\
\hline $\begin{array}{l}\text { Hernández, S., Losada, C. y } \\
\text { Matilla, K. }\end{array}$ & 2009 & $\begin{array}{l}\text { "Las relaciones públicas y la comunicación corpo- } \\
\text { rativa en la oferta universitaria del posgrado del } \\
\text { Estado Español: análisis sistemático y proyectivo y } \\
\text { una iniciativa de observatorio del estado de la si- } \\
\text { tuación por parte de una asociación profesional”. }\end{array}$ & Razón y Palabra \\
\hline $\begin{array}{l}\text { Navarro, C., Moreno, A. y } \\
\text { Zerfass A. }\end{array}$ & 2012 & $\begin{array}{l}\text { “Análisis longitudinal de la profesión de relaciones } \\
\text { públicas en España en los últimos cinco años } \\
\text { (2007-2011)”. }\end{array}$ & $\begin{array}{l}\text { Anagramas: rumbos y senti- } \\
\text { dos de la comunicación }\end{array}$ \\
\hline $\begin{array}{l}\text { Míguez, M.I. y Baamonde, X. } \\
\text { M. }\end{array}$ & 2011 & $\begin{array}{l}\text { "La evolución de las relaciones públicas hacia la di- } \\
\text { rección de comunicación: aproximación histórica } \\
\text { en el contexto académico español". }\end{array}$ & Razón y Palabra \\
\hline
\end{tabular}




\begin{tabular}{|l|l|l|l|}
\hline Autores & Año & Artículos & Revista \\
\hline Paniagua, C. & 2010 & $\begin{array}{l}\text { “Una historia de la comunicación de crisis en Es- } \\
\text { paña”. }\end{array}$ & $\begin{array}{l}\text { Icono 14. Revista de Comu- } \\
\text { nicación Audiovisual y } \\
\text { nuevas tecnologías }\end{array}$ \\
\hline \multirow{2}{*}{ Reina, J. } & 2014 & $\begin{array}{l}\text { "Antecedentes de las relaciones públicas en la } \\
\text { prensa malagueña de principios del siglo XX”. }\end{array}$ & $\begin{array}{l}\text { Ámbitos: Revista internacio- } \\
\text { nal de comunicación }\end{array}$ \\
\cline { 2 - 5 } & 2015 & $\begin{array}{l}\text { "Relaciones con los medios a finales del siglo XIX: } \\
\text { antecedentes de los comunicados de prensa en la } \\
\text { prensa malagueña". }\end{array}$ & $\begin{array}{l}\text { Revista Mediterránea de co- } \\
\text { municación. Mediterranean } \\
\text { Journal of communication }\end{array}$ \\
\hline Reina, J. y González, M.I. & 2014 & $\begin{array}{l}\text { "Antecedentes de las relaciones públicas en los ma- } \\
\text { nuales de publicidad. Algunos precedentes de } \\
\text { actividad en España desde mediados del siglo XIX”. }\end{array}$ & Vivat Academia \\
\hline $\begin{array}{l}\text { Reina, J., González, M.I. y } \\
\text { Matilla, K. }\end{array}$ & 2014 & $\begin{array}{l}\text { “Prat Gaballí y Juan Beneyto: una aproximación a la } \\
\text { introducción de la disciplina de las relaciones pú- } \\
\text { blicas en España". }\end{array}$ & $\begin{array}{l}\text { Revista Internacional de Re- } \\
\text { laciones Públicas }\end{array}$ \\
\hline
\end{tabular}

Fuente: Elaboración propia

Existen diferencias entre el porcentaje de artículos obtenidos en cada base de datos, ya que en Dialnet se ha encontrado el 84,6\% de los textos (13 artículos) mientras que de ISOC se ha recuperado el 53,8\% de los documentos (9 artículos). Cabe señalar que un $61,5 \%$ de los escritos analizados se ha localizado en una única base de datos mientras que un $38,5 \%$ de los textos ha aparecido en las dos bases de datos utilizadas.

\section{Resultados}

\subsection{El nacimiento de las relaciones públicas en España}

La literatura existente en España sobre el origen de las relaciones públicas en nuestro país sitúa los primeros pasos en la década de los sesenta, precedida por un breve periodo de antecedentes en los años cincuenta (Almansa, 2004). La literatura referida a esa primera época parece centrarse en la simple relación de acontecimientos sin una gran profundización en el tema. Esta falta de interés podría estar motivada porque autores como Arceo (2006) consideraban que las verdaderas relaciones públicas no aparecieron hasta el final de la dictadura, momento a partir del cual se incrementa la investigación sobre la disciplina. 
No obstante, en los últimos años, diferentes investigadores (Almansa, 2004; Gutiérrez y Rodríguez, 2009; Armendáriz, 2012; Reina, 2014a; Reina 2014b; Reina y González, 2014) han analizado las características de las acciones comunicativas que se llevaron a cabo antes de la década de los años 50, ya que en ellas es posible rastrear, a juicio de estos autores, una incipiente actividad de relaciones públicas que podrían ser considerados como antecedentes del área.

La investigación de Reina (2014a: 59), apoyada en el análisis de la prensa malagueña de principios del siglo XX, muestra que "en un momento en que ni siquiera en Norteamérica se había producido el verdadero surgimiento de la profesión, las empresas malagueñas locales, a través de la intuición y de la experiencia, aún sin poseer un bagaje teórico sobre el que apoyarse, empiezan a valerse de las herramientas de relaciones públicas para dar a conocer su organización”.

Son numerosos los ejemplos que detalla Rodríguez Salcedo² (2007) en su investigación o los casos que analiza Armendáriz $^{3}$ (2012). Ambos establecen un claro vínculo entre relaciones públicas y propaganda en una época en la que España todavía no había sufrido la influencia norteamericana. Reina y González ${ }^{4}$ (2014a; 2014b), por su parte, también aportan antecedentes y recuperan esa parte de la historia de la publicidad cuando consideran que las acciones de relaciones públicas recibieron una denominación laboral errónea bajo el amparo de la publicidad. En cualquier caso, los autores que han investigado estos precedentes consideran que la aparición de las relaciones públicas en España se produce avant la lettre (Armendáriz, 2012; Reina y González, 2014a) gracias a la existencia de una tradición propia (Reina, 2014a) anterior a la llegada de las tropas estadounidenses durante la II Guerra Mundial, tal y como señala Arceo (2006).

Además, estos autores señalan que, mientras que el origen norteamericano de las relaciones públicas sitúa sus comienzos profesionales en el ámbito periodístico de finales del siglo XIX (Reina, 2014a), los primeros indicios de actividad relacionada con las relaciones públicas en España surgen a finales del siglo XIX y principios del siglo XX (Gutiérrez y Rodríguez, 2009; Reina y González, 2014; Reina, 2015) en el ámbito de la publicidad. De este modo, durante sus inicios, las relaciones públicas se emplearon como una herramienta más al servicio de las agencias de publicidad y fueron en muchas

2 Rodríguez (2007) cita el caso protagonizado por la compañía suiza Nestlé en 1881 como ejemplo de "publicidad redaccional". La compañía insertó textos de apariencia periodística en La Ilustración Española y Americana. El artículo explicaba las características y propiedades de uno de sus productos, la harina lacteada. Otro de los antecedentes que cita la autora es el de Perfumeras Gal a principios de los años 30. La empresa llevó a cabo una campaña publicitaria educativa en la que se enseñaba a los niños el correcto cepillado de los dientes.

3 Armendáriz (2012) cita el caso de la empresa alemana fabricante de aviones Junkers en los años 20 como una campaña de propaganda recogida en una novela de Arturo Barca (2000). Otra de las referencias aportadas por Armendáriz y recogida en una obra de Pío Baroja (2006) hace referencia a una revista, El Cortador, como ejemplo de prensa corporativa del sector carnicero de la época.

4 Reina (2014) realiza "un estudio en el que se muestran algunos de los antecedentes de relaciones públicas localizado en la prensa malagueña del primer tercio del siglo XX". Entre los antecedentes destaca la existencia de "visitas de empresa como técnica temprana de relaciones públicas", "los regalos de empresa como recordatorio de marca", "la prensa corporativa" o "los comunicados de prensa" como acciones de comunicación enmarcadas en el ámbito de las relaciones públicas. 
ocasiones etiquetadas erróneamente (y reflejadas en los manuales de uso académico) como acciones publicitarias (Reina y González, 2014).

Sin embargo, otros autores, como Arceo (2006: 111), indican que los antecedentes antes señalados de las relaciones públicas no pueden considerarse referentes válidos, ya que la falta de libertad durante "la dictadura del general Franco impidió que hubiese actividad de relaciones públicas propiamente dichas hasta la segunda mitad de los años setenta”. No obstante, según Armendáriz (2012: 16), aceptar la tesis de Arceo implicaría negar una tradición de relaciones públicas española "que hunde sus raíces en la publicidad, la propaganda comercial y la propaganda a secas (según terminología de la propia época), y con las que comparte una serie de técnicas y herramientas comunes".

\subsection{Evolución del concepto de "relaciones públicas" a "dirección de comunicación"}

Si bien las condiciones políticas y socioeconómicas que existían en los años 50 en España distaban mucho de las que ampararon los orígenes de las relaciones públicas en Estados Unidos (Gutiérrez y Rodríguez, 2009), el fin del aislamiento internacional de España tras la II Guerra Mundial y la mejora del entorno económico, coadyuvaron al desarrollo de las primeras campañas de relaciones públicas (Reina y González, 2014).

Según Armendáriz (2012: 19), a partir de esta década "las relaciones públicas, concebidas desde una vertiente puramente comercial, cobrarán protagonismo aunque las técnicas de las que se vale la disciplina estarán plenamente consolidadas desde mucho tiempo antes, tanto en el ámbito comercial como en el institucional y político, y recibirán en muchos casos el nombre de propaganda, aunque acompañada frecuentemente del adjetivo comercial".

A pesar de las primeras incursiones de la disciplina en la sociedad de mediados de siglo, para la mayoría de los académicos el inicio oficial de la profesión en España se fija a mediados de la década de los años sesenta, con el uso consciente y reconocido del término "relaciones públicas" (Almansa, 2005; Gutiérrez y Rodríguez, 2009). Este reconocimiento, traducido en la creación de los primeros gabinetes de prensa, se produce después de que la disciplina norteamericana desembarque en el continente europeo a través de Francia durante la II Guerra Mundial (Arceo, 2006).

Esta etapa también se caracteriza por los intentos asociativos que se iniciaron con el objetivo de dotar a la disciplina de un reconocimiento profesional. Así pues, la Asociación Técnica de Relaciones Públicas (ATRP), creada en 1961 en Madrid, supone el primer intento asociativo, aunque apenas sobrevivió un par de años. En 1965 se crea la Agrupación Española de Relaciones Públicas (ARP) en Barcelona y en este mismo año nace en Madrid el Centro Español de Relaciones Públicas (CENERP) (Gutiérrez y Rodríguez, 2009). Gracias a estas asociaciones y al empuje de profesionales reconocidos como Joaquín Maestre, interesado por las tendencias y la visión europea del área, se llevaron a cabo durante estos años importantes actividades relacionadas con las relaciones públicas a escala nacional e internacional. Sin embargo, como 
indican Gutiérrez y Rodríguez (2009), a pesar de todos los esfuerzos por consolidarse, los intentos asociativos acontecidos en esta época fracasaron.

Como señala Almansa (2004: 9), "la especialización de funciones, es decir, la profesionalización y la consolidación de estructuras organizadas, llega en la década de los sesenta con el nacimiento de los primeros gabinetes de prensa". Sin embargo, la juventud de la disciplina y la inmadurez de la profesión hacía que la mayoría de los profesionales que trabajaban en estos departamentos lo hiciera con el objetivo principal de resolver problemas que pudieran presentarse en situaciones de crisis (García, 2011). En palabras de Paniagua, "solían desempeñar con cierta insistencia el oficio de 'bomberos', cuya obligación era evitar posibles perjuicios que pudieran ocasionar algunas informaciones realizadas con afán crítico o no elogioso" (Paniagua, 2010: 6).

Para autores como Arceo (2006), la llegada de la democracia en 1975, generó un nuevo entorno imprescindible para que pudiera desarrollarse la actividad de las relaciones públicas en España. En este nuevo contexto, el sector comunicativo experimentó grandes cambios que se hicieron visibles con un crecimiento acelerado en la oferta y la demanda informativa (Gutiérrez y Rodríguez, 2009). Esta situación provocó la proliferación de fuentes distintas (partidos políticos y asociaciones que dejan de estar en la clandestinidad y empresas con nuevas necesidades comunicativas) a las que se manejaban hasta entonces (las propias instituciones) (Alamansa, 2004; García, 2011). Las nuevas fuentes de información surgen potenciadas por la libertad de prensa. Ante este panorama "se acaba el statu quo que se había mantenido en las relaciones entre las empresas y la prensa, ahora dispuesta a informar sin miramientos" (Paniagua, 2010:8).

Pero a pesar de ello, los principales sectores industriales del país, como las telecomunicaciones, la energía y los transportes, siguieron siendo monopolios del Estado hasta finales de los años 80 (Gutiérrez y Rodríguez, 2009). En esta época los medios, y principalmente la prensa, tienen un papel relevante para influir en la sociedad. "Las empresas iban percibiendo la importancia que tenía una buena imagen, que gozara de una percepción favorable por la opinión pública” (Paniagua, 2010: 9), y así nace la necesidad de profesionalizar la relación empresa-medios (Paniagua, 2010). Por este motivo, en los nuevos gabinetes de prensa se incorporan profesionales con un perfil periodístico, ya que una de sus principales funciones (si no la única) era cubrir las necesidades informativas de los medios de comunicación. Así, las empresas, mayoritariamente públicas, crearon departamentos vinculados a esta actividad que se amparaban también bajo una amplia terminología: gabinetes de relaciones públicas, asesorías de relaciones públicas o comunicación, gabinetes de comunicación o gabinetes de prensa (Almansa, 2004).

Instituciones y empresas demandan la incorporación de profesionales internos o externos (agencias o consultoras) que gestionen la comunicación de sus empresas. Las organizaciones contemplan en sus organigramas los "gabinetes de comunicación" (Almansa, 2004; Míguez y Baamonde, 2011) y proliferan las empresas y asesorías de comunicación, llegando incluso a producirse las primeras incursiones de agencias internacionales de relaciones públicas (Gutiérrez y Rodríguez, 2009). 
Por otro lado, la liberación económica que hubo en el país planteó un entorno económico muy diferente al vivido hasta el momento. "La privatización de empresas públicas, la integración de nuestro país en la Comunidad Económica Europea y la posterior internalización de las empresas españolas” favorecen el desarrollo de la comunicación corporativa (García, 2011: 27). La mayor oferta de productos y servicios hace necesario que las empresas ofrezcan "un mensaje corporativo que las diferencie en el mercado y, sobre todo, que transmita de forma unívoca su identidad corporativa” (Gutiérrez y Rodríguez, 2009).

Todos estos cambios aportan una complejidad especial a la hora de distribuir la información y dirigirse a unos públicos determinados y, a su vez, favorecen la implantación de departamentos o gabinetes de comunicación (Almansa, 2004; Gutiérrez y Rodríguez, 2009), herederos de los "gabinetes de prensa y de relaciones públicas", pero con más funciones asignadas (Almansa, 2004; Almansa, 2005). El peso de los intangibles empieza a ser relevante para las empresas y, en especial, la gestión de la reputación (Gutiérrez y Rodríguez, 2009), pero estos primeros profesionales, aunque contaban con el conocimiento de las técnicas y de las rutinas informativas, "desconocían aspectos relevantes como la gestión de la marca o la construcción de la identidad corporativa” (García, 2011).

Ante la amplificación de funciones y el nuevo entorno, se crea la necesidad de perfilar una nueva figura profesional que sea capaz de integrar todas las comunicaciones que llevan a cabo las organizaciones. Si hasta ahora las empresas cubrían sus necesidades comunicativas, principalmente técnicas, con profesionales de disciplinas especializadas (periodismo, publicidad o relaciones públicas), ahora surge la necesidad de un gestor generalista. Esta figura nace de "la necesidad de las empresas de 'racionalizar' sus actividades comunicativas e impulsar una mayor coordinación entre áreas diferentes y un mejor aprovechamiento de los recursos existentes" (García, 2011).

En este contexto no tardará en surgir la figura del director de comunicación (dircom), que tiene sus orígenes en Francia en los años 80. Sin embargo, el afianzamiento de esta figura (y la dirección de comunicación) no ve su reflejo en la reflexión teórica y académica hasta los 90. En estos años el papel del dircom "llegó a adquirir una especial relevancia por sus conocimientos de cultura corporativa, management, políticas de responsabilidad corporativa, comunicación interna y comunicación online" (García, 2011). Los departamentos experimentan una necesidad de división de funciones como consecuencia de la complejidad de los procesos comunicativos, de las necesidades de comunicación interna o de su relación con los stakeholders (García, 2011).

Esta década fue también la época del asociacionismo en el sector (Almansa, 2004; Paniagua, 2010; Gutiérrez y Rodríguez, 2009). En 1991 se creó la Asociación Española de Empresas Consultoras en Relaciones Públicas y Comunicación (ADECEC). Tan solo un año más tarde, en 1992, nace la Asociación de Directivos de Comunicación (ADCDircom). Curiosamente, mientras la patronal incluye la expresión "relaciones públicas" y excluye la de "dircom", la asociación profesional de directivos de comunicación DIRCOM, no incluye la primera expresión en su acrónimo (Estanyol y Lalueza, 2014; Gutiérrez 
y Rodríguez, 2009). De este modo, la denominación elegida por la mayor asociación del sector ha abandonado la terminología "relaciones públicas" apostando por el término "dircom".

Vemos cómo la gran eclosión de la nueva disciplina viene refrendada por el apoyo del ámbito profesional, aunado en las principales asociaciones del sector (ADECEC y DIRCOM), siendo estas mismas asociaciones las que han llevado a cabo "las investigaciones más ambiciosas para conocer el estado de la profesión en España" (Gutiérrez y Rodríguez, 2009).

\subsection{Personajes e hitos relevantes en la evolución práctica profesional y la teoría}

Así como en Estados Unidos se reconoce unívocamente a Ivy Lee como el padre de las relaciones públicas, en España numerosos académicos atribuyen este reconocimiento a Joaquín Maestre y Joan Viñas (Almansa, 2004; Armendáriz, 2012; Paniagua, 2010; Navarro et al. 2012). Estos profesionales, provenientes del ámbito de la publicidad y la propaganda, han sido considerados fundamentales para la consolidación de la disciplina en España y serán ellos quienes, según Armendáriz (2012), inicien la actividad bajo el nombre de "relaciones públicas" en 1959. Este mismo año fundan en Barcelona la primera agencia especializada en el área en España: la S.A.E. de RP, Sociedad Anónima Española de Relaciones Públicas (Paniagua, 2010).

Otra circunstancia relevante en la consolidación de la disciplina fue, según apuntan Gutiérrez y Rodríguez (2009), el encuentro fortuito entre Joaquín Maestre y Lucién Matrat ${ }^{5}$, padre y filósofo de las relaciones públicas europeas. Este encuentro que tuvo lugar durante un congreso de publicidad organizado en Amberes cambió la visión de Maestre sobre el ejercicio profesional que él mismo desarrollaba. Al parecer, los planteamientos de Matrat sobre las relaciones públicas

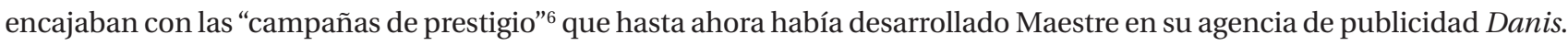
Estas campañas han sido consideradas tradicionalmente como los antecedentes históricos directos de la disciplina en España. Como se sabe, la agencia de publicidad Danis, fundada por Joan Fontcuberta a finales de la década de los 50 en Barcelona, dotaba a sus campañas de la forma de "publicidad social” (Gutiérrez y Rodríguez, 2009).

Por otro lado, Reina (2015) afirma que "es posible rastrear una incipiente actividad paralela de relaciones públicas en Madrid, incluso anterior en el tiempo a la catalana, puesta en marcha por la agencia Ruescas Publicidad” (Reina, 2015: 60). De este modo, es posible ver en los textos analizados cómo desde una investigación más reciente encontramos un grupo de

5 Lucien Matrat fue el fundador de la escuela de París y representante de la doctrina europea de las relaciones públicas. Si bien "sus principios beben de las ideas de autores norteamericanos como Bernays, Cutlip, Center, Canfield, Moore y Lesly” (Xifra, 2006), esta escuela se caracteriza por ser profundamente humanista, "basada en el concepto de confianza como elemento central" y esto supone aceptar "conciliar el interés de la empresa y el de quienes dependen de su progresión” (Xifra, 2006).

6 Eran campañas que intentaban mejorar la sociedad de la época y que otorgaban prestigio a la marca. "No pretendían la venta de un producto, sino que eran un apunte de programa social que pretendía una mejora de nuestra relación humana y que repercutió en un ambiente de buena voluntad para el producto y la firma que lo fabricaba" (Noguero, 1995: 140). 
académicos españoles que difiere del reconocimiento de las campañas llevadas a cabo por Danis como pioneras, y que al mismo tiempo considera que el publicista Pedro Prat Gaballí es "el verdadero introductor en España de la publicidad y las relaciones públicas" (Gutiérrez y Rodríguez, 2009; Rodríguez, 2010; Reina y González, 2014), pese a que sus prácticas no fueran amparadas bajo esa nomenclatura. Para estos académicos él fue el primer autor que hizo referencia al concepto $\mathrm{Pu}$ blic Relations en su obra "Publicidad Combativa" (1953), aunque su traducción del término fue relaciones generales (Gutiérrez y Rodríguez, 2009; Reina y González, 2014). El mismo Prat Gaballí, en el citado texto, se remonta a 1911 para referirse a la primera campaña de publicidad que le fue encargada y en la que denominaba publicidad redaccional a la publicación de artículos con la intención de generar ideas positivas en torno a una empresa y cuya finalidad última es económica (Armendáriz, 2012).

Como se refleja en todos los antecedentes históricos, la indeterminación terminológica ${ }^{7}$ (Reina y González, 2014) y la práctica de la profesión bajo otras rúbricas (Armendáriz, 2012; Reina y González, 2014), caracteriza la primera etapa de las relaciones públicas en España, reflejo según afirman Reina y González (2014), de la falta de delimitación de los fundamentos teóricos.

La misma corriente de autores cita a Beneyto como otra de las figuras clave en el desarrollo teórico de la disciplina en España y sus obras, junto con las de Gaballí, son consideradas como una referencia para comprender el surgimiento de las relaciones públicas en este país (Gutiérrez y Rodríguez, 2009; Reina Estévez 2014). Así pues, la obra “Mass Communication. Un panorama de los Medios de Información en la Sociedad Moderna”, publicada por Beneyto en 1957, es considerada como el primer libro que utiliza el término relaciones públicas (Gutiérrez y Rodríguez, 2009; Reina y González, 2014).

Durante los años setenta se avanza notablemente en la formación de la disciplina de las relaciones públicas en España. Su aparición universitaria se produce en 1968 con la creación de la Escuela Superior de Relaciones Públicas en la Universidad de Barcelona. Posteriormente, en 1974, se aprueba provisionalmente el primer plan de estudios que recoge esta materia, pero no es hasta la década de los noventa (1991) cuando se establece el título universitario oficial (BOE n. 234, de 30 de septiembre), que sustituye el antiguo título de Ciencias de la Información por tres licenciaturas autónomas y diferenciadas: Periodismo, Comunicación Audiovisual y Publicidad y Relaciones Públicas. Es en este momento cuando las relaciones públicas adquieren el rango de licenciatura y la disciplina queda vinculada académicamente al ámbito de la publicidad.

\footnotetext{
“Montero, Rodríguez y Verdera (2010:193) parten del plano profesional para confeccionar una lista de términos vinculados a las relaciones públicas en los años previos al nacimiento de la disciplina (...) relaciones generales, publicidad de servicios, campañas de propaganda, acción social, publicidad educativa o publicidad de prestigio" (Reina y González, 2014).

8 Periodismo (Real Decreto 1427/1991 de 30 de agosto), Publicidad y Relaciones Públicas (Real Decreto 1386/1991 de 30 de agosto) y Comunicación Audiovisual (Real Decreto 1428/1991 de 30 de agosto).
} 
En este contexto académico de los años 90 y coincidiendo con la eclosión de la figura del dircom, se contempló el desarrollo del marco teórico que sustenta esta nueva corriente de la dirección de comunicación o comunicación corporativa (García, 2011). Mucha de la reflexión teórica sobre la dirección de comunicación en otros países procede del propio ámbito de las relaciones públicas y tiene grandes similitudes con la visión ofrecida por Grunig y Hunt en Excellence in Public Relations and Communication Management (1992). No en vano, los últimos cambios académicos siguen mantenido la vinculación que desde sus inicios universitarios las relaciones públicas han tenido con la publicidad, pero por otro lado apreciamos cómo en documentos como el Libro Blanco ${ }^{9}$ de la ANECA o en los planes de estudios de determinadas universidades se vislumbra la influencia de la corriente de la comunicación corporativa (Hernández et al., 2009). Así pues, para referirse a los perfiles profesionales adscritos para el Título de Grado en Publicidad y Relaciones Públicas indica que son aquellos que "ejercen su actividad desde el ámbito de las organizaciones o desde una agencia o desde la empresa consultora y profesionales responsables de la gestión estratégica de la comunicación corporativa” (Hernández et al., 2009: 5).

\subsection{Concomitancias y puntos de inflexión}

Hay autores que constatan que "en España el concepto de relaciones públicas sobre el que se trabaja en el ámbito académico está desapareciendo del mundo empresarial e institucional, mientras que está proliferando el uso de otros términos como "dirección de comunicación" para reflejar las funciones de gestión integral de la comunicación que han de realizarse en una empresa" (Míguez y Baamonde, 2011: 2). En esta misma línea, Gutiérrez y Rodríguez (2009) subrayan que en las últimas décadas, términos como comunicación corporativa parecen imponerse a la denominación de relaciones públicas.

No obstante, cuando se analiza "el concepto de dirección de comunicación encontramos que, dado el estrecho vínculo entre comunicación y relaciones públicas, las referencias a esta disciplina son inevitables” (Míguez y Baamonde, 2011: 5) y que gran parte de la reflexión teórica sobre la dirección de comunicación, procede del ámbito de las relaciones públicas (Míguez y Baamonde, 2011). A pesar de ello a nivel académico nos encontramos con "unos cimientos científicos siempre en discusión (Hernández et al., 2009), situación que plantea la existencia de distintas posturas.

En la década de los setenta, y "en la misma época que las relaciones públicas comienzan a afianzar su visión directiva (...), florecen en el ámbito empresarial y académico otros conceptos, como el de comunicación integral” (Míguez y Baamonde, 2011: 6). Para Míguez y Baamonde, estas dos visiones "tratan de dar respuesta a una misma necesidad: que la comunica-

9 Bajo la titulación de Publicidad y Relaciones Públicas se pretende capacitar para el ejercicio profesional en cuatro perfiles básicos, de los que sólo uno encaja plenamente con la comunicación corporativa y las relaciones públicas, el gestor de Comunicación Corporativa, si bien, el enfoque integrador que lo define, también admite de forma parcial el perfil de Director de Comunicación, Investigador y Consultor Estratégico en [Publicidad] y Relaciones Públicas (ANECA, 2005). 
ción sea una actividad que se coordina y se desarrolla no sólo desde el punto de vista técnico, sino como una función de dirección relevante dentro de la empresa" (Míguez y Baamonde, 2011: 6), como una herramienta de gestión (Almansa, 2005).

Independientemente del punto de vista a partir del cual se trate la cuestión, "todos los autores que abordan la dirección de comunicación coinciden en que debe ocupar un lugar relevante en el organigrama” (Míguez y Baamonde, 2011: 7) y formar parte de la alta dirección de la empresa (Navarro et al., 2012), de modo que "la función comunicativa tiende a considerarse una herramienta estratégica" (Gutiérrez y Rodríguez, 2009: 29) al servicio de la misma. Sin embargo, "es en la función de definiciones donde hay más fricciones y más confusión entre la dirección de comunicación y las relaciones públicas" (Míguez y Baamonde, 2011: 8).

Muchos autores coinciden en que la dirección de comunicación debe gestionar la comunicación en su totalidad, tanto externa como interna (Almansa, 2005; Gutiérrez y Rodríguez, 2009), y a partir de ahí, incorporará entre otras funciones la coordinación de la publicidad y considerará las relaciones públicas como una parte esencial (Míguez y Baamonde, 2011). En este mismo sentido, Almansa (2005) afirma que "gran parte de las tareas que se atribuyen al dircom son de relaciones públicas" (Almansa, 2005: 122).

Dentro de la confusión terminológica existente en el ámbito de la comunicación, encontramos también la referida al órgano o departamento que se encarga de llevar a cabo las funciones relacionadas con la comunicación dentro de la estructura de la organización. "Existe una terminología muy amplia y que, en la mayoría de los casos, sirve para denominar un mismo fenómeno" (Almansa, 2005: 119): "Gabinete de comunicación, gabinete de prensa, departamento de comunicación, dirección de comunicación, dircom, asesoría de comunicación...”.

Desde sus inicios, "el campo de conocimiento de las relaciones públicas y la comunicación corporativa está íntimamente unido al desarrollo profesional” (Hernández et al. 2009: 2). El nacimiento de la disciplina se produjo primero en el ámbito profesional y motivado por las necesidades de las empresas (Gutiérrez y Rodríguez, 2009). Es por ello que en el inicio de la actividad en España, los primeros profesionales pertenecieron a diferentes ámbitos como la propaganda o la publicidad. Sin embargo, con la creación de los gabinetes de prensa, y la relevancia que adquirieron los medios, la profesión se ejercía principalmente desde el periodismo. Actualmente, "aunque empieza a reconocerse que el trabajo desarrollado por los gabinetes de comunicación es de relaciones públicas, se sigue asociando la actividad al mundo del periodismo" (Almansa, 2005: 129), y aunque la presencia en los medios sigue preocupando en las organizaciones, hoy el concepto de comunicación es mucho más complejo y se contempla como un todo que incluye la publicidad y las relaciones públicas (Almansa, 2005).

Este concepto global de la comunicación acerca más el perfil profesional a la titulación de publicidad y relaciones públicas y lo distancia en mayor media de la titulación de periodismo. 


\section{Conclusiones}

La literatura dedicada a la historia de la profesión establece que el nacimiento de las relaciones públicas en España estuvo marcado por los patrones de investigación estadounidenses (Arceo, 2006; Xifra, 2010). Pese a ello, nuestra primera conclusión es que, en la actualidad, no hay consenso sobre el origen de la disciplina en España y a este respecto existen diferentes corrientes.

Por un lado, una corriente dominante que los sitúa en los años sesenta, con un breve período de antecedentes (Almansa, 2011; Castillo, 2009; Noguero, 1995, 2004; Xifra, 2010). Por otro, otra postura académica que fija la implantación de la disciplina en los años setenta, una vez se inicia la democracia (Arceo, 1999; Arceo, 2004a; Arceo, 2004b; Arceo, 2006). Finalmente, los autores más recientes establecen los orígenes de la actividad de las relaciones públicas en España a finales del XIX y principios del XX, en forma de antecedentes aislados, en ocasiones enmascarados con otros términos o asumidos por disciplinas tales como la publicidad o la propaganda (Armendáriz, 2012; Montero et al., 2010; Reina, 2014a; Reina, 2014b; Reina y González, 2014; Rodríguez, 2007).

Sí parece haber acuerdo, y esta sería una segunda conclusión, en cuanto al ámbito de aparición de la disciplina: tradicionalmente se ha considerado que se produjo en el seno de la publicidad, a través de la actividad de las agencias (Rodríguez, 2010) y en forma de campañas de prestigio o publicidad social.

Como tercera conclusión, destacamos la unanimidad en situar el origen de las "relaciones públicas" como disciplina en Estados Unidos a mediados del siglo XIX y su desarrollo profesional, teórico y académico en el siglo XX. Sin embargo, no ocurre lo mismo respecto a la llegada del término a España, apreciando diferentes posturas: por un lado los que consideran que se implanta bajo una influencia norteamericana (Arceo, 2006) y por otro lado los que reivindican la visión francesa y las aportaciones de Lucien Matrat (Míguez y Baamonde, 2011).

En este punto debemos matizar, que si bien las nuevas investigaciones sobre los orígenes remotos de la actividad de relaciones públicas en España defienden la existencia de indicios previos al siglo XX, en ningún caso podrían considerarse como relevantes en el origen de la disciplina, puesto que carecían de cualquier base teórica y se basaban únicamente en la intuición.

En cuarto lugar, constatamos no solo el origen difuso de implantación de la disciplina en España, sino también la existencia de diferentes hitos y personajes de relevancia considerados como los pioneros en el desarrollo tanto profesional como teórico de la disciplina.

En quinto lugar, la presente investigación ha encontrado también que la reflexión sobre la naturaleza y el concepto comunicación corporativa y su relación con las relaciones públicas genera divergencias. En este caso también se dan cuatro visiones diferentes: 
- $\quad$ Por un lado, aquellos que entienden la comunicación corporativa como una función amplia que incluye muchos elementos entre los que están la publicidad y las relaciones públicas. Para esta vertiente el término "relaciones públicas" está obsoleto y solo representa una serie de técnicas (Míguez y Baamonde, 2011)

- $\quad$ Por otro lado, hay quienes consideran que las relaciones públicas y la comunicación corporativa son sinónimos. Para estos autores las funciones que se le atribuyen a ambos términos son similares. Consideran que, desde un punto de vista académico, la comunicación corporativa y la dirección de comunicación está por construir. Desde esta perspectiva es innegable la vinculación que existe entre la comunicación corporativa y las relaciones públicas, y defienden la coexistencia de ambos conceptos apelando a las relaciones públicas como fundamento teórico de la nueva disciplina (Almansa, 2004; Gutiérrez y Rodríguez, 2009).

- $\quad$ En tercer lugar, y como apuntan Míguez y Baamonde (2011), existe un grupo de autores para los que el término relaciones públicas está condenado a desaparecer. Los principales motivos aducidos por los investigadores son las connotaciones negativas que envuelven al término (Paniagua, 2010; Gutiérrez y Rodríguez, 2009), la falta de reconocimiento social (Almansa, 2004) y la confusión acerca de la propia profesión.

- $\quad$ Finalmente, académicos que defienden la existencia del término "relaciones públicas", no admiten la evolución de la disciplina hacia la comunicación corporativa y tampoco reconocen su vinculación con términos como "reputación" o “dirección de comunicación”. Esta corriente, con autores como Arceo, aboga por la evolución del concepto de "relaciones públicas" al que ahora se le han ido incorporado a lo largo del tiempo nuevas funciones y el rango de "directivo". Esta corriente considera innecesario utilizar nuevos términos para denominar el concepto evolucionado de las relaciones públicas.

Nuestra conclusión a este respecto es que a pesar de encontrar diferentes posturas sobre la evolución y la relación de los términos, hoy por hoy, es innegable la vinculación entre las relaciones públicas y la comunicación corporativa en el contexto académico español. Así, lo demuestra la propia búsqueda bibliográfica realizada para acometer la presente investigación. En la compilación final de los textos, encontramos cómo todos los artículos obtenidos en las búsquedas en las que se han utilizado las palabras clave "dirección de comunicación” o “comunicación corporativa”, aparecen simultáneamente en aquellas otras búsquedas resultantes de la inclusión del término "relaciones públicas" como palabra clave.

Finalmente, cabe señalar como la principal limitación de este trabajo el haber examinado únicamente artículos científicos, lo que implica rechazar otras importantes fuentes de información, como por ejemplo, la literatura gris.

A partir de los resultados extraídos en esta investigación, consideramos interesante profundizar en los antecedentes más remotos de la actividad de relaciones públicas para, como propone Reina (2014), poder reivindicar las acciones de relaciones públicas que históricamente recibieron una denominación laboral errónea en el ámbito de la publicidad. 


\section{Referencias bibliográficas}

Almansa, A. (2004): “Historia de los gabinetes de comunicación en España”, Historia y comunicación social, n. 9, pp. 5-21.

- (2005): “Relaciones públicas y gabinetes de comunicación”, Anàlisi: quaderns de comunicació i cultura, pp. 117-132.

- (2011): Del gabinete de prensa al gabinete de comunicación: la dirección de comunicación en la actualidad. Zamora: Comunicación Social y Publicaciones.

Arceo, J. L. (2006): “La investigación de relaciones públicas en España”, Revista Análisi. Quaderns de Comunicació i Cultura, n. 34, pp. 111-124.

Armendáriz, E. (2012): "Relaciones Públicas pioneras en España. Algunos precedentes en la primera mitad del siglo XX y pasos preliminares de la nueva profesión”, Revista Análisi. Quaderns de Comunicació i Cultura, n. 45, pp.15-31.

Castillo, A. (2009): Relaciones Públicas: teoría e historia. Barcelona: Editorial UOC.

Costa, J. (1995): Comunicación corporativa y revolución de los servicios. Madrid: Ed. Ciencias Sociales.

- (2001): "El director de comunicación. La nueva figura central en la empresa del siglo XXI", en VVAA: Dirección de Comunicación empresarial e institucional (47-66). Barcelona: Gestión 2000.

- (2009). El Dircom hoy. Dirección y gestión de la comunicación en la nueva economía. Barcelona: Costa Punto Com Editor.

Estanyol, E. y Lalueza, F. (2014): “ $i$ Tamaño o flexibilidad? Estructura organizativa de las consultoras de relaciones públicas en España”, Sphera Publica, pp. 135-162.

García-Santamaría, J.V. (2011): "Los responsables de comunicación en la empresa española desde la década de los setenta hasta hoy día: evolución de funciones y perfiles profesionales”, Revista Internacional de Relaciones Públicas, vol. 1, n. 2 pp. 25-40.

Gutiérrez, E. y Rodríguez, N. (2009): “Cincuenta años de relaciones públicas en España. De la propaganda y la publicidad a través de la gestión de la reputación”, Doxa Comunicación, n. 9, pp. 9-33.

Martín, F. (1997): Comunicación en empresas e instituciones. De la consultora a la dirección de comunicación. Salamanca: Ediciones Universidad de Salamanca.

Míguez, M. I. y Baamonde Silva, X. M. (2011): “La evolución de las relaciones públicas hacia la dirección de comunicación: aproximación histórica en el contexto académico español”, Razón y Palabra, n. 75.

Montero, M., Rodríguez, N. y Verdera, F. (2010): “De la nada al consumo. Desde los orígenes hasta 1960”, en Historia de la publicidad y de las relaciones públicas en España, vol. 1. Sevilla, Zamora: Comunicación Social.

Noguero, A. (1995): La función social de las relaciones públicas: Historia, teoría y marco legal. Barcelona: EUB.

Paniagua, C. (2010): “Una historia de la comunicación de crisis en España”, ICONO 14, n. 8, pp. 3-24. 
Reina, J. (2014a): “Antecedentes de relaciones públicas en la prensa malagueña de principios del siglo XX”, Ámbitos: Revista internacional de comunicación, n. 27, pp. 51-60.

- (2014b). "Relaciones con los medios a finales del siglo XIX: antecedentes de los comunicados de prensa en la prensa malagueña”, Revista Mediterránea de Comunicación: Mediterranean Journal of Communication, n. 6, pp. 59-82.

Reina, J. y González, M. I. (2014): “Antecedentes de relaciones públicas en los manuales de publicidad. Algunos precedentes de actividad en España desde mediados del siglo XIX", Vivat Academia, año XVII, n.128, pp. 1-20.

Rodríguez, N. (2007): La historia como tendencia actual de las relaciones públicas. Ponencia presentada en el Congreso Tendencias actuales de las Relaciones Públicas de la Asociación de Investigadores en Relaciones Públicas (AIRP).

Villafañe, J. (1999): La gestión profesional de la imagen corporativa. Madrid: Pirámide.

Xifra, J. (2010): Relaciones Públicas, empresa y sociedad. Barcelona: Editorial UOC. 